\title{
Reaction Between Nitrogen and Spinel in Chromium
}

\author{
D. M. SCRUGGS, ${ }^{*}$ L. H. VAN VLACK, and W. M. SPURGEON \\ Bendix Rescarch Laboratories, Southfield, Michigan 48075, and \\ Departuent of Chanical and Metallurgical Engincering, University of Michigan, Aan Arbor, Michigan 48104
}

The reaction between nitrogen dissolved in chromium and a dispersion of magnesium aluminate particles in chromium at high temperatures is discussed. The equilibrium state for various nitrogen concentrations in a 94 chromium-6 spinel mixture was investigated between $1200^{\circ}$ and $1400^{\circ} \mathrm{C}$. Experimental techniques included electron-beam microprobe analysis and mass spectrometry. Partitioning of nitrogen between chromium and spinel was strongly in favor of the spinel. Mass spectrometry indicated coordination of nitrogen with magnesi$\mathrm{um}$ in the spinel lattice. The spinel-nitrogen reaction is important because it can prevent the embrittling of chromium by nitrogen.

\section{Introduction}

I INTERACTION between metals and ceramics is assuming greater importance as the demands of our technology increase. Strengthening of metals with ceramic dispersoids or with fibers and whiskers has received considerable attention. Modification of alloys by ceramic additions has also been attempted, primarily to increase hardness or heat resistance.

These modifications have proved very useful despite the lowering of ductility in the composite which ustally occurs. This investigation concerns an exception to this effect on ductility; that is, the considerable decrease in the brittleductile transition temperature of commercially pure chromium by the addition of a spinel or spinel-forming oxide. In general, ductility as measured by elongation is reduced at any given temperature when a ceramic is added to a metal, but when spinel is added to chromium a ductilizing effect more than offsets this normal embrittlement because the brittle-ductile transition temperature is reduced.

This spinel effect is believed to be unique. It was first described $^{1}$ in the system $\mathrm{Cr}-\mathrm{MgO}-\mathrm{Cr}_{2} \mathrm{O}_{3}$. A powder metallurgy preparation of $94 \mathrm{Cr}-6 \mathrm{MgO}$ had a brittle-ductile transition below room temperature with from 20 to $24 \%$ elongation at room temperature, which represented a drop in transition temperature of nearly $400^{\circ} \mathrm{C}$. X-ray examination of phases extracted from the composite showed that considerable quantities of magnesium chromite spinel had formed during sintering by reaction of $\mathrm{Cr}_{2} \mathrm{O}_{3}$ in the powder with $\mathrm{MgO}$. ()n the basis of this work, the hypothesis of the present work was that spinels absorb nitrogen dissolved in chromium and thus effectively remove it from the matrix, rendering the matrix ductile.

Nitrogen is presently thought to be the chief cause of the brittle behavior of chromium at low temperatures. ${ }^{2-8} \mathrm{Ex}$ planations of the embrittling phenomena vary, however: some investigators favor Cottrell locking,4; others, straininduced precipitation ${ }^{5}$; and some favor the action of nitride precipitates. ${ }^{6-8}$ The extremely low solubility of nitrogen in chromium (Fig. 1) contributes to the uncertainty, as it is "lifficult to make valid chemical analyses and to observe the various mochanisms. As little as 3 ppm of nitrogen has been reported to embrittle chromitum. ${ }^{9}$

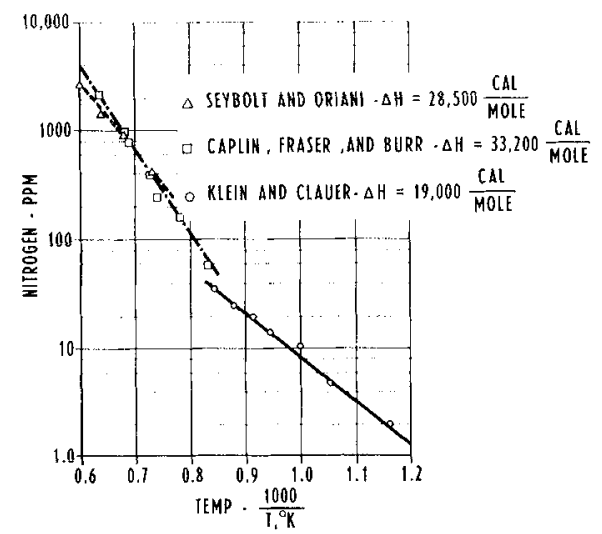

Fig. 1. Solubility of nitrogen in chromium according to the van't Hoff equation (Ref. 3 ).

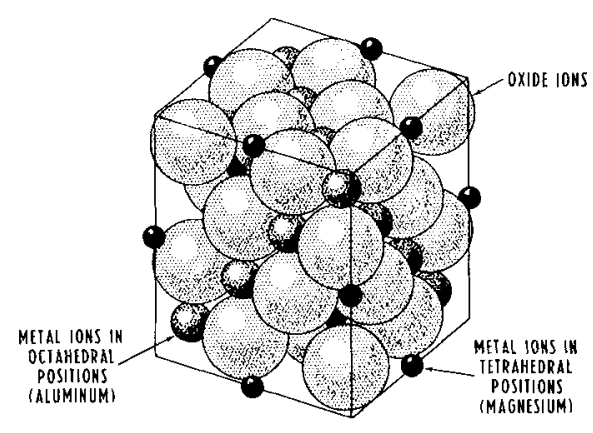

Fig. 2. Normal spinel lattice.

The prototype spinel, magnesium aluminate, was selected as the oxide of primary interest because of its stability and because it contains no chromium. Magnesium chromite was also studied briefly.

The following description of the spinel structure was taken from a description by Blasse. ${ }^{10}$

The unit cell of normal spinel structure is shown in Fig. 2. In the ideal crystal the anions form a close-packed cubic

Presented at the Fall Meeting of the Ceramic-Metal Systems Division of The American Ceramic Society, French Lick, Indiana, September 13, 1967 (Paper No. 19-C-67F). Received December 11, 1967; revised copy received April 26, 1967.

Based in part on a thesis submitted by D. M. Scruggs for the Doctor of Philosophy degree in engineering materials at the University of Michigan.

At the time this work was done, the writers were, respectively, senior engineer, Bendix Research Laboratories; professor, Department of Chemical and Metallurgical Engineering, University of Michigan; and head, Materials and Processes Departnent, Bendix Research Laboratories.

* Now assistant professor, Department of Mechanical Enginecring, University of Arkanisas, Fayetteville Arkansas 72701. 
Table I. Raw Material Impurities

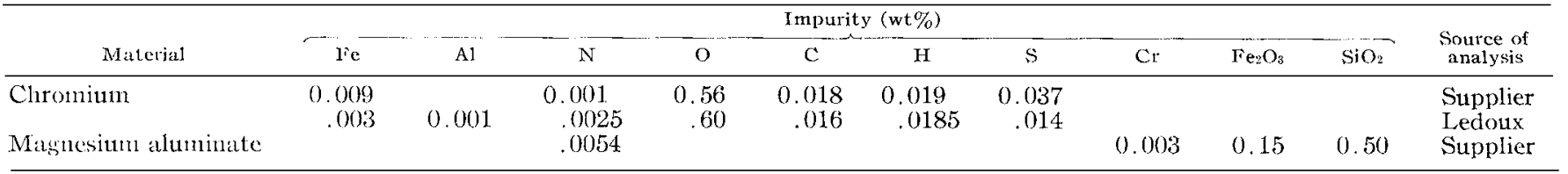

structure in which the cations occupy a fraction of the tetrahedral and octahedral interstices. There are 32 anion positions in the tnitit cell, resulting in 64 tetrahedral and 32 octahedral positions. Eight tetrahedral sites (called $A$ sites) are occupied by divalent ions, and 16 octahedral sites (called $B$ sites) are occupied by trivalent ions. A nonideal structure is derived from the ideal one by moving the anions in a [111] direction away from the nearest tetrahedral ion.

According to ligand-field thery, the octahedral site preference for $\mathrm{Cr}$ is stabilized by about $40 \mathrm{kcal} / \mathrm{mole}^{10}$ For other ions, the site preference is less than half this energy. Consequently, other spinels feature trivalent ions in both $A$ and $B$ sites. Blasse listed 147 binary spinels recorded through 1963. Nitrogen occurred in these spinels only as the cyanicle ion.

Adams et $a{ }^{11}$ earlier reported a spinel in the system $\mathrm{Al}_{2} \mathrm{O}_{3}-\mathrm{AlN}$, corresponding to the formula $\mathrm{Al}_{3} \mathrm{O}_{3} \mathrm{~N}$. They wrote $\gamma-\mathrm{Al}_{2} \mathrm{O}_{3}$ as a defect spinel:

$$
\mathrm{A}_{8 / 3} \square_{\mathrm{i} / 3} \mathrm{O}_{4}
$$

where $\square$ is a cation vacancy. For every aluminum atom ackled to fill a vacancy in formula (1), charge compensation is achieved by replacing three oxygen ions with nitrogen ions. Thus, $\mathrm{Al}_{3} \mathrm{O} \mathrm{O}_{3} \mathrm{~N}$ is obtained by adding one third of an aluminum. to formula (1) and compensating with the substitution of one nitwogen for one oxygen:

$$
\mathrm{Al}_{\mathrm{y} / 3} \mathrm{O}_{33} \mathrm{~N}
$$

or

$$
\mathrm{Al}_{3} \mathrm{O}_{3} \mathrm{~N}
$$

These writers also doped $\mathrm{Al}_{3} \mathrm{O}_{3} \mathrm{~N}$ spinel with chromiutn and concluded that $\mathrm{Cr}^{3+}$ would substitute for $\mathrm{Al}$ in octahedral sites only.

The effects of nonstoichiometry on possible reactions are of considerable interest. Anderson ${ }^{12}$ in a survey of the consequences of nonstoichiometry on the behavior of refractory materials, stated that in the distorted spinel $\mathrm{A}_{2} \mathrm{BO}_{4}$ the coordination structures are based. on the close packing of oxygens, and the encrgy of the substitutional defect pair is determined principally by cation size. Furthermore, this energy is usually small, and all such compounds are likely to undergo this limited type of order-disorder transition at high temperatures.

Anderson referred to the work of Altman and Searcy, ${ }^{13}$

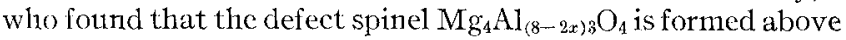
$1800^{\circ} \mathrm{K}$, and to an investigation by Beban of the reduction of $\mathrm{CaO}$ with metallic calcium. Only in the presence of calcinun vapor and nitrogen was a highly colored product formed. The material contaited from 0.85 to $1.03 \mathrm{Ca} / \mathrm{N}$. Incorporation of nitrogen amounts virtually to the creation of anion vacancies. Anderson stated further that excess electrons may be trapped as $F$ centers, as altervalent cations, or as a defect pair of zero virtual charge. The close correlation between excess calcium and nitrogen ions suggests that defect pairs were only slightly dissociated at $1150^{\circ}$ to $1200^{\circ} \mathrm{C}$ and that an excess of calcium was needed to force nitrogen into the essentially ionic structure.

\section{Experimental Procedure}

Materials and procedtres were selected to deternine the mechanisin of ductility cnlaneenent. Equilibrium studies were done to determine the amounts of constituents involved

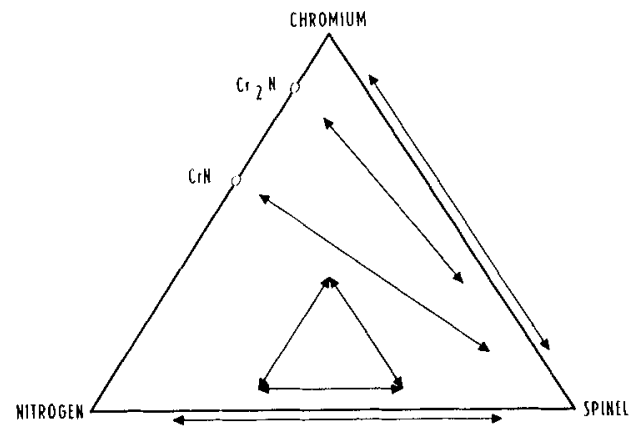

Fig. 3. System Cr-spinel-N. Arrows indicate component combinations investigated.

and analytical techniques were used to determine nitrogen content.

\section{(1) Materials}

Ground electrolytic chromium* which analyzed $99.2 \%$ pure with oxygen as the principal impurity was used. The powder was -325 mesh (Tyler sieve), peaking at a particle size of 10 to $12 \mu$. Magnesium aluminate was prepared by fusion of stoichiometric amounts of high purity magnesium oxide and aluminum oxide. This material was a -200 mesh powder (Tyler sieve). Magnesium oxide and magnesium chromite were also used for control purposes. Chemical analyses of the raw materials are given in Table I. Gases $\$$ used were prepurified grades of anhydrous ammonia and nitrogen and standard grade argon and oxygen.

Monochromium nitrice was prepared by passing ammonia over copper turnings at $700^{\circ} \mathrm{C}$ and then over the chromium powder at the same temperature for $24 \mathrm{hr}$. X-ray diffraction of the restlting powder gave a pattern identical to that listed in the ASTM index for monochromium nitride. Dichromium nitride was made by the same procedure, except that the temperature was $1300^{\circ} \mathrm{C}$. X-ray analysis demonstrated that the resulting powder was pure dichromium nitride.

\section{(2) Experimental Method}

Figure 3 shows the combinations of components for which the possibility of reaction was investigated. Significant combinations include chromium-nitrogen, which has already been studied by Seybolt and Oriani ${ }^{14}$ and by Caplin et al..$^{15}$; spinelmonochromium nitride; spinel-dichromium nitride; and spincl-nitrogen. Assuming that dissociation of the spinel is insignificant, the system can be considered ternary. The combination of most concern includes all three components; the binaries are of interest only for elucidating the mechanism of the reaction. Procedures for the phase equilibrium studies were:

(1) Determination of nitrogen reaction with spinels and magnesium oxide, requiring furnace treatment of the oxides in molecular and nascent nitrogen atmospheres above $1000^{\circ} \mathrm{C}$.

* Elchrone-LG, Union Carbide Corporation, New York, New York.

† Muscle Shoals Electrochenical Company, 'Tuscumbia, Alabama.

¥ Matheson Corporation, East Rutherford, New Jersey. 
(2) Study of the equilibrium between chromium nitrides and spincl, using furnace treatment of powder mixtures of the materials from $500^{\circ}$ to $1445^{\circ} \mathrm{C}$ in dissociated ammonia.

(3) Examination of the equilibritm compositions and structures in the system chromium, spinel, and nitrogen, which involved exposure of samples of wrought chromjumspincl composites to nitrogen at low temperatures, equilibration at $1.200^{\circ}, 1300^{\circ}$, and $1400^{\circ} \mathrm{C}$, and subsequent analysis.

For the nitrogen reaction with spinel, fused silica boats containing a $15 \mathrm{~g}$ powder sample were heated in an $80 \%$ argon$20 \%$ oxygen mixture for $2 \mathrm{hr}$ at the temperatures listed in Table II. The samples were cooled and then weighed on an analytical balance. The boats were then heated in purified nitrogen for $3 \mathrm{hr}$ at the same temperature and reweighed. The samples to be exposed to nascent nitrogen were heated in anhydrous ammonia gas which had passed through copper turnings heated to $900^{\circ} \mathrm{C}$. The gas in the furnace was checked with the ammonia quality apparatus described by Bullens ${ }^{16}$; the dissociation was more than $95 \%$ complete.

Reaction of chromium nitrides with spinels was similarly studied, using samples blended and spread evenly in the bottom of fused silica boats held in an ammonia atmosphere at various temperatures for 24 and $100 \mathrm{hr}$. The monochromium nitride-spinel mixtures were heated at temperatures from $5000^{\circ}$ to $1000^{\circ} \mathrm{C}$, and dichromium nitride-spinel mixtures from $12000^{\circ}$ to $1500^{\circ} \mathrm{C}$. Exact lattice parameters of the spinel and of the nitrides were determined by $\mathrm{X}$-ray diffraction.

Composite specimens used in studying the chromium-spinelnitrogen system were prepared by powder metallurgy methods, i.e. blending of chromium and spinel powders, pressing at $15,000 \mathrm{psi}$, sintering in palladium-purified hydrogen for 4 hr at $14500^{\circ} \mathrm{C}$, and extruding at $1200^{\circ} \mathrm{C}$ with a $10: 1$ area reduction. Bar samples were then equilibrated with varying quantitics of nitrogen.

A direct method used by Seybolt and Oriani, ${ }^{14}$ who determined equilibrium partial pressures of nitrogen in contact with pure chromitum at saturation, was first attempted. They found the equilibrium pressures at $1200^{\circ}, 1300^{\circ}$, and $14010^{\circ} \mathrm{C}$ to be $6.6 \pm 0.5,10 \pm 1$, and $43.5 \pm 0.5 \mathrm{~mm} \mathrm{Hg}$, respectively. These pressures were maintained and regulated by a controlled flow of argon and nitrogen, which were gettered and introduced into a tube furnace. This method of nitriding at low pressures was not entirely suitable, however, because rather high temperatures were needed to achieve the larger nitrogen contents. Seybolt and Oriani pointed out that chromium is an excellent oxygen getter at $1200^{\circ} \mathrm{C}$ and above and begins vaporizing at $1300^{\circ} \mathrm{C}$.

A capsule method of studying the system was therefore used, eliminating the problems of oxidation and vaporization. Bars of the composite weighing approximately $10 \mathrm{~g}$ were nitrided at $1000^{\circ}$ and $1100^{\circ} \mathrm{C}$ for various times. At these temperatures the use of prepurified nitrogen, further purified by passage over hot copper turnings as described by Seybolt and Oriani, resulted in a reproducible weight change in the sample. A slight tarnish was evident but no green oxide formed, and no evidence of chromium vaporization was noted. These samples were then sealed in evacuated fused silica capsules, heated for $48 \mathrm{hr}$ at $1200^{\circ}, 1300^{\circ}$, and $1400^{\circ} \mathrm{C}$, and quenched in ice-brine. No visible reaction occurred between the samples and the silica. Phases in the resulting samples were identified metallographically. A transverse section of each specimen was broken off, cold-mounted, and polished. The appearance of primary nitride (formed at equilibrium and present before quenching) and precipitated nitride represented the significant data points.

Kingery ${ }^{17}$ discussed the difficulties of using phase disappearance in equilibrium studies, the principal one being that of identifying a new phase by microscopy or by X-ray diffraction. He stated that as much as $10 \%$ of a new phase may be necessary for the X-ray method, but as little as $0.5 \%$ for microscopy. An attempt to lower the limit for microscopy was made in this study by using the electron microscope for com-
Table II. Weight Changes During Exposure of $\mathrm{MgO}, \mathrm{MgAl}_{2} \mathrm{O}_{4}$, and $\mathrm{MgCr}_{2} \mathrm{O}_{4}$ to Nitrogen

\begin{tabular}{|c|c|c|c|}
\hline $\begin{array}{c}\text { Temp }) \\
\left({ }^{\circ} \mathrm{C}\right)\end{array}$ & Sample & $\begin{array}{l}\text { Time } \\
\text { (hr) }\end{array}$ & Wt change $(\mathrm{g} / \mathrm{g})$ \\
\hline \multicolumn{4}{|c|}{ Molecular nitrogen } \\
\hline 1100 & $\mathrm{MgAl}_{2} \mathrm{O}_{4}$ & 3 & -0.007 \\
\hline " & $\mathrm{MgCr}_{2} \mathrm{O}_{4}$ & 3 & +.001 \\
\hline$"$ & $\mathrm{MgO}$ & 3 & .000 \\
\hline 1200 & $\mathrm{MgAl}_{2} \mathrm{O}_{4}$ & 3 & .000 \\
\hline ", & $\mathrm{MgO}$ & 3 & -.001 \\
\hline \multicolumn{4}{|c|}{ Dissociated ammonia } \\
\hline 1200 & $\mathrm{MgAl}_{2} \mathrm{O}_{4}$ & 3 & .000 \\
\hline ", & $\mathrm{MgCr}_{2} \mathrm{O}_{4}$ & 3 & .000 \\
\hline 1445 & $\mathrm{MgAl} 2 \mathrm{O}_{4}$ & 4 & $150 \mathrm{ppm} \mathrm{N}_{2}{ }^{*}$ \\
\hline$"$ & $\mathrm{MgCr}_{2} \mathrm{O}_{4}$ & 4 & 170 ppm $N_{2}^{*}$ \\
\hline 1500 & $\mathrm{MgCr}_{2} \mathrm{O}_{4}$ & 4 & $\begin{array}{l}300 \mathrm{ppm} \mathrm{N} \mathrm{N}_{2}^{*} \\
-0.01\end{array}$ \\
\hline
\end{tabular}

* By chemical analysis.

positions near the phase boundary; the electron microscope was essential for distinguishing between small nitride particles and etch pits. Specimens for electron microscopy were prepared by two-stage plastic replication. Platinum carbon shadowing at a low angle $\left(30^{\circ}\right)$ intensified the contrast of fine structures.

Analyses for chromium and other metallic elements were performed by emission spectrography. Nitrogen analyses were by the Kjeldahl method. Electron microanalysis was used for selected samples to provide a qualitative in situ determination of nitrogen. Electron-beam microprobe analyses were conducted with a tungsten emitter; a lithium stearate crystal, and a flow counter on standard ARL units EMX and AMX. Standards were based on the nitrogen peak emitted from boron nitride and dichromium nitride.

Temperatures below $1200^{\circ} \mathrm{C}$ were measured with ChromelAlumel thermocouples cemented to the furnace tube wall at the position of the sample. Temperatures above $1200^{\circ} \mathrm{C}$ were measured with a W-W26Re thermocouple in hydrogen and ammonia and with a Pt-Pt13Rh thermocouple in air and argon.

A Reichart Vacutherm hot-stage microscope was used to study the microstructure from room temperature to $900^{\circ} \mathrm{C}$ at a vacuum of $5 \times 10^{-6}$ torr.

A Bendix Time-of-Flight mass spectrometer, model 1111, was used to identify mass numbers of gaseous products emitted by the chromium-spinel composite from room temperature to $800^{\circ} \mathrm{C}$ in high vacuum.

\section{Results}

\section{(1) Spinel-Nitrogen}

The weight changes which occurred on heating magnesium oxide, magnesium aluminate, and magnesium chromite with atomic and molecular nitrogen ate given in Table II. The data clearly indicate that no reaction takes place at $1100^{\circ}$ or $1200^{\circ} \mathrm{C}$ between any of the oxides and nitrogen in either form. At very high temperatures, some nitrogen absorption occurs in the spinels.

The portion of the investigation concerned with the oxidenitrogen system thus indicates two specific results:

(1) Magnesium aluminate, magnesium chromite, and magnesium oxide are chemically inert to atomic or molecular nitrogen at $1100^{\circ}$ and $1200^{\circ} \mathrm{C}$.

(2) A small quantity of nitrogen reacts with spinels above $1400^{\circ} \mathrm{C}$, resulting in a pickup of a few hundred parts per million nitrogen.

\section{(2) Spinel-Chromium Nitrides}

The chromium content of magnesium aluminate spinel equilibrated with chromium nitrides, as determined by lattice 


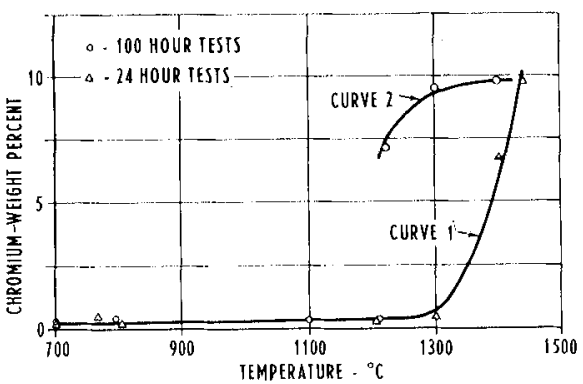

Fig. 4. Chromium content of spinel heated with mixed chromium nitrides (curve 1) and with chromium (curve 2), as a function of temperature. No difference in chromium content was noted between temperatures where $\mathrm{CrN}$ is more stable, $700^{\circ}$ to $800^{\circ} \mathrm{C}$, and the temperature region where $\mathrm{Cr}_{2} \mathrm{~N}$ is more stable, $1100^{\circ}$ to $1200^{\circ} \mathrm{C}$.

parameter shift, is shown in curve 1, Fig. 4 . X-ray diffraction of the samples after equilibration indicated mixed $\mathrm{Cr}_{2} \mathrm{~N}$ and $\mathrm{CrN}$ from $750^{\circ}$ to $1000^{\circ} \mathrm{C}$ and $\mathrm{Cr}_{2} \mathrm{~N}$ only above $1200^{\circ} \mathrm{C}$. Little reaction was evident up to $1300^{\circ} \mathrm{C}$. Coloring of the spinel (pink) confirmed the observations. Faint coloring appeared at $1300^{\circ} \mathrm{C}$ and deepened considerably at $1445^{\circ} \mathrm{C}$.

This phase of the experiments indicated that chromium readily dissolves in magnesium aluminate above $1300^{\circ} \mathrm{C}$, but no reliable chemical analysis could be made for nitrogen because of the difficulty of separation. No new phase appeared in the spinel at any of the temperatures investigated.

\section{(3) Chromium-Spinel-Nitrogen}

Exposure to nitrogen and subsequent analysis of bars of wrought chromium containing $6 \%$ spinel (magnesium aluminate) was the last part of the component study. Samples made from pure chromium powder, without spinel, contained about $50 \mathrm{ppm}$ nitrogen and had quantities of precipitated nitrides in the extruded condition, in agreement with previous work.

Samples of chromium containing 6 wt $\%$ spinel behaved quite differently. No nitrides were present after fabrication and extrusion. The samples were then exposed to varying gluantities of nitrogen at $1000^{\circ}$ and $1100^{\circ} \mathrm{C}$. When the nitrogen charge exceeded the solubility limit, a nitride case was formed. This case disappeared, however, when the samples were held at temperature. Microstructures, after heating for $18 \mathrm{hr}$, were free of nitrides and were equivalent to structures of samples heated for 48 hr. Turkdogan and Ignatowicz ${ }^{18}$ reported that equilibrium was reached after 48 to 72 hr above $1100^{\circ} \mathrm{C}$ in studies of nitrogen equilibration with ironchromium alloys.

To ensure equilibrium, all the samples were held for 48 hr at $1200^{\circ}, 1300^{\circ}$, and $1400^{\circ} \mathrm{C}$. As the amount of nitrogen in the samples increased, the chromium was first completely free of nitrides or any other feature; more nitrogen caused pitting after etching with a $3: 1$ glycerine- $\mathrm{HCl}$ solution. Quantities of etch pits appeared, and finally, needles of nitride were scen as excess nitrogen caused well-defined primary nitride crystals to form at the equilibration temperature. These were first noted in the grain boundaries.

X-ray examination of spinels extracted with brominemethanol from three control samples which were unnitrided but equilibrated at $1200^{\circ}, 1300^{\circ}$, and $1400^{\circ} \mathrm{C}$, respectively, demonstrated that spinel in the chromium matrix absorbed more chromium at $1200^{\circ}$ and $1300^{\circ} \mathrm{C}$ than when heated with dichromium nitride. After cooling, many spinel grains contained a precipitated chromium phase. The chromium content computed by lattice paraneter shift is shown in curve 2, Fig. 4.

The heat-treated 94 chromium-6 spinel composites can be divided into two classes: those which contain acicular nitride

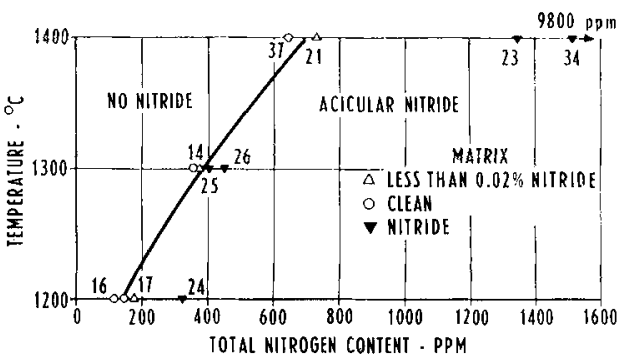

Fig. 5. Acicular nitride phase in $94 \mathrm{Cr}-6$ spinel composite as a function of nitrogen content and temperature. Pure $\mathrm{Cr}$ without spinel exhibits acicular nitride at 15 to $25 \mathrm{ppm}$ nitrogen level. Data points are coded with sample numbers.

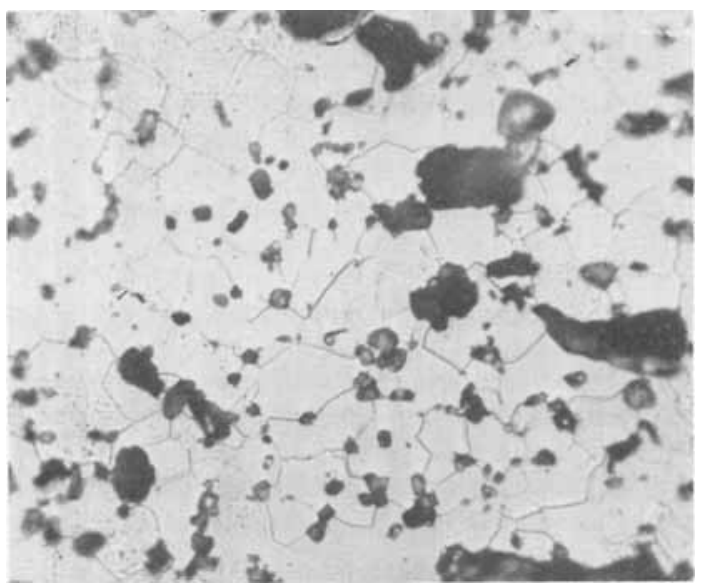

Fig. 6. Sample 16, with 140 ppm nitrogen, equilibrated at $1200^{\circ} \mathrm{C}$. Very little pitting and no nitride needles. Dark areas are spinel of widely varying grain size. $\mathrm{HCl}$-glycerine etch $(\times 900)$.

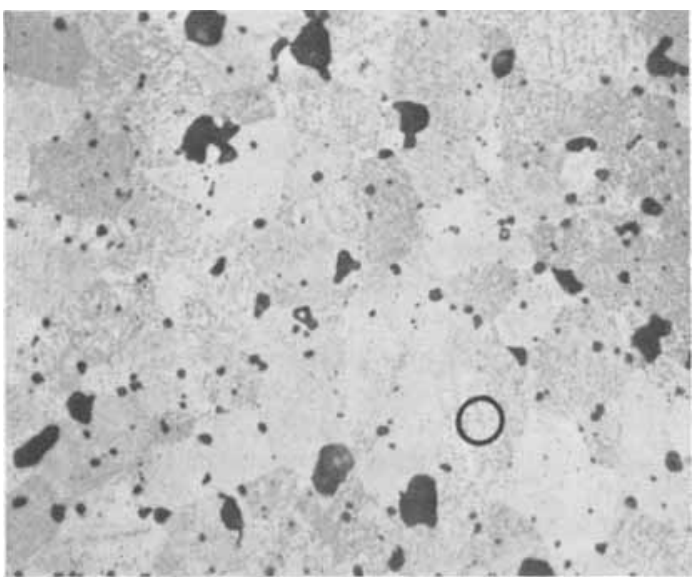

Fig. 7. Sample 17, with $180 \mathrm{ppm}$ nitrogen, equilibrated at $1200^{\circ} \mathrm{C}$. Very extensive etch pitting, as shown in circled area, but no nitride needles. HCl-glycerine etch $(\times 900)$.

precipitates, and those which do not. Pure electrolytic chromium control samples (without spinel) similarly processed but not exposed to nitrogen exhibited gross nitride precipitates after treatment at all temperatures.

The composition points for extruded 94 chromium- 6 spinel are plotted in Fig. 5. A boundary line separates the compositions with and without acicular nitride precipitates at room temperature. Electron microscopy was used to identify 


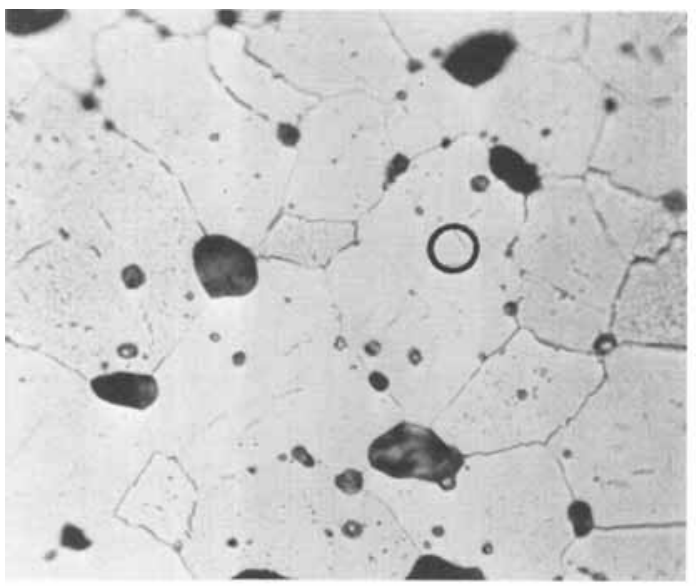

Fig. 8. Sample 21, with $730 \mathrm{ppm}$ nitrogen, equilibrated at $1400^{\circ} \mathrm{C}$. A few widely separated nitride needles as shown in circled area. HCl-glycerine etch $(\times 900)$.

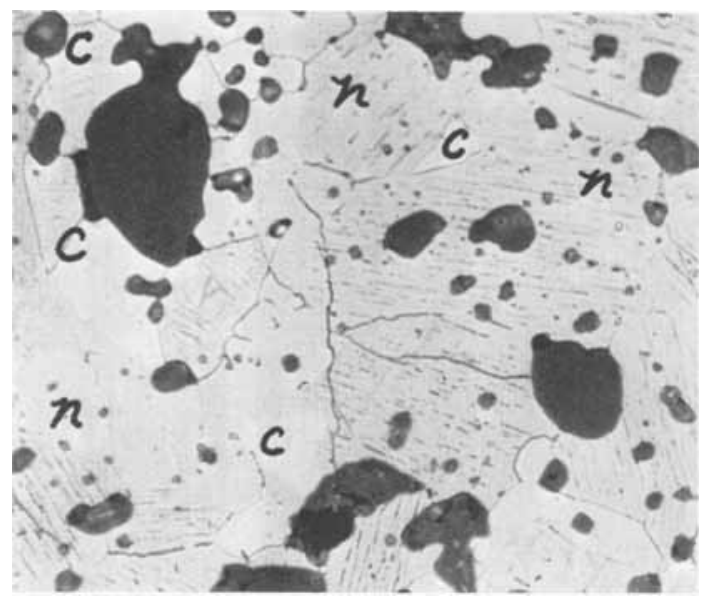

Fig. 9. Sample 34, with $9800 \mathrm{ppm}$ nitrogen, equilibrated at $1400^{\circ} \mathrm{C}$. Contains $\mathrm{Cr}$ with nitride needles (areas marked $c$ ), and $\mathrm{Cr} N$ with $\mathrm{Cr}$ needles (areas marked $n$ ). HCl-glycerine etch $(\times 500)$.

nitrides in the samples. Characteristic microstructures are shown in Figs. 6 through 10.

\section{(4) Chemical Analysis}

In the Kjeldahl method, the chromium-spinel sample is first digested with $\mathrm{HCl}$. The spinel is not dissolved and can be separated by filtration. Nitrogen contents of the separated spinels were extremely low and quite variable. The solutions tested high in nitrogen and gave consistent results. In view of the microstructures, the only explanation was that the portion of the spinel that contained the nitrogen was dissolved by $\mathrm{HCl}$. This result suggested the possibility of microanalysis in situ with an electron-beam microanalyzer.

\section{(5) Electron-Beam Microprobe Analysis}

Recently developed techniques for analysis of the soft $\mathrm{X}$ rays emitted by nitrogen were used. An electron-beam microanalyzer was used to examine individual oxide crystals at random in sample 34 which was equilibrated at $1400^{\circ} \mathrm{C}$. The nitrogen peak was scanned for maximum reading with boron nitride. A chromium-spinel sample not exposed to nitrogen and containing $50 \mathrm{ppm}$ total nitrogen was used for the background count. Essentially the results are as would be expected, except that the oxides in sample 34 could be

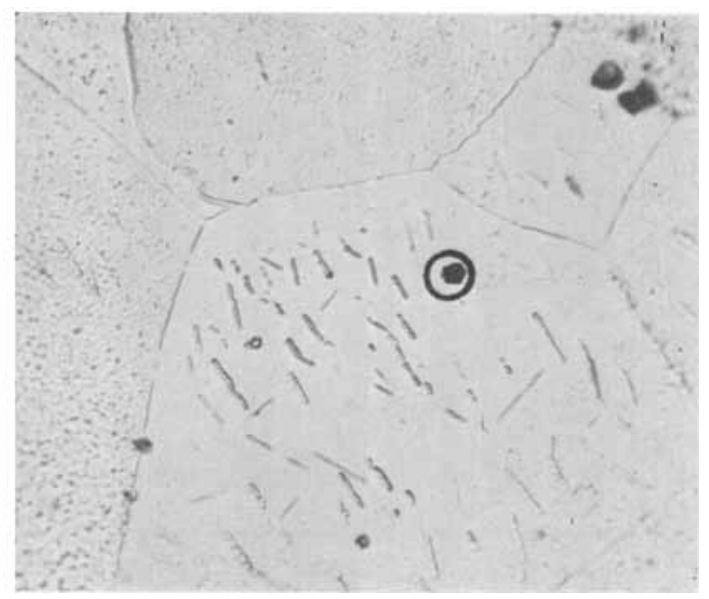

Fig. 10. Sample 20 , with 420 ppm $\mathrm{N}$, equilibrated at $1200^{\circ} \mathrm{C}$. Large chromium grains, many containing large nitride needles. Circle encloses a chromium oxide particle. HCI-glycerine etch $(\times 500)$.

Table III. Electron-Beam Microprobe Determination of Nitrogen in Sample 34 (Nitrogen Content $0.098 \%$ )

\begin{tabular}{lcc}
\multicolumn{1}{c}{ Phase } & $\begin{array}{c}\text { Mean } \\
\text { (cts/sec) }\end{array}$ & $\begin{array}{c}\text { Sample } \\
\text { size, } n\end{array}$ \\
\hline Cr nitride, $\mathrm{Cr}_{2} \mathrm{~N}$ & 2014 & 5 \\
Cr needles & $246^{*}$ & 10 \\
Cr grains & $224 \dagger$ & 10 \\
Oxides, low $\mathrm{N}_{2}$ content & 173 & 37 \\
\hline
\end{tabular}

* Neglecting a reading of 485 .

$\uparrow$ Neglecting readings of 637,684 , and 380 .

Table IV. Nitrogen X-Ray Emission in Selected Spinel Crystals in Sample 34*

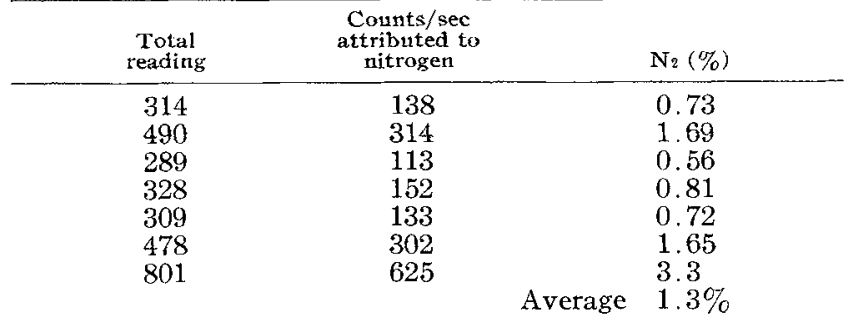

* These crystals have statistically significant nitrogen contents computed on the basis of $11 \% \mathrm{~N}_{2}$ in $\mathrm{Cr}_{2} \mathrm{~N}$.

separated into two groups, one group apparently containing no nitrogen. Results are given in Tables III and IV.

The random appearance of nitrogen from one oxide particle to another posed serious questions of distribution and chemical activity. The full composition of single oxide crystals in situ was therefore investigated. It seemed highly possible that $\mathrm{AlN}$ or $\mathrm{Mg}_{3} \mathrm{~N}_{2}$ was present, so that careful sample preparation was necessary because of their property of rapid hydrolysis. Samples for metallography and microprobe analysis were cut and polished in absolute alcohol; no water or etchants were used and very little heat was generated in mounting and grinding.

Electron backscatter of an interesting area is shown in Fig. 11. Several oxide particles of varying size and shape are in the area. One of particular interest is centered in the photograph and shows a concentration of heavy element 


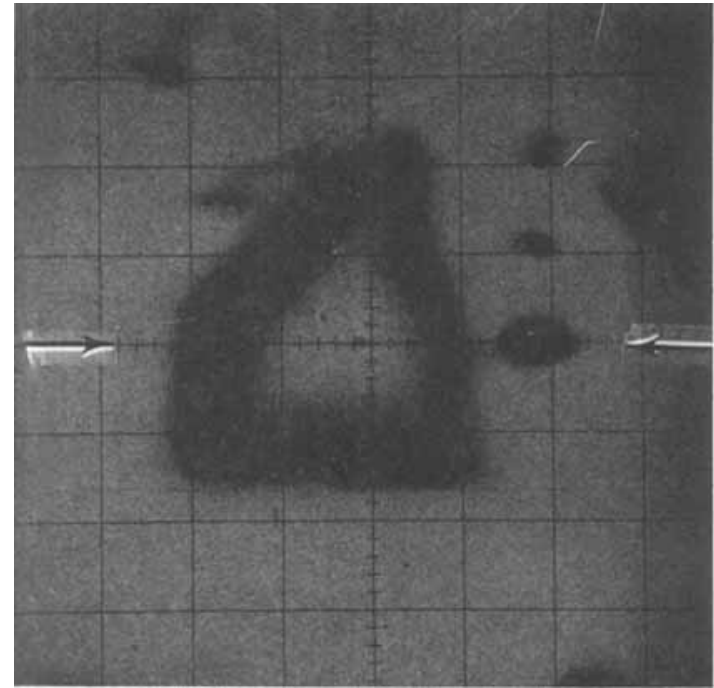

Fig. 11. Electron-beam microprobe photograph of electron backscatter of sample 43 , area (1), no etch $(\times 1200)$. A line trace made along the grid marked with arrows appears in Fig. 15. Composition of the large oxide grain is apparently somewhat different than that of the smaller oxides. Sample was equilibrated at $1300^{\circ} \mathrm{C}$ and has a nitrogen content of 1360 ppm.

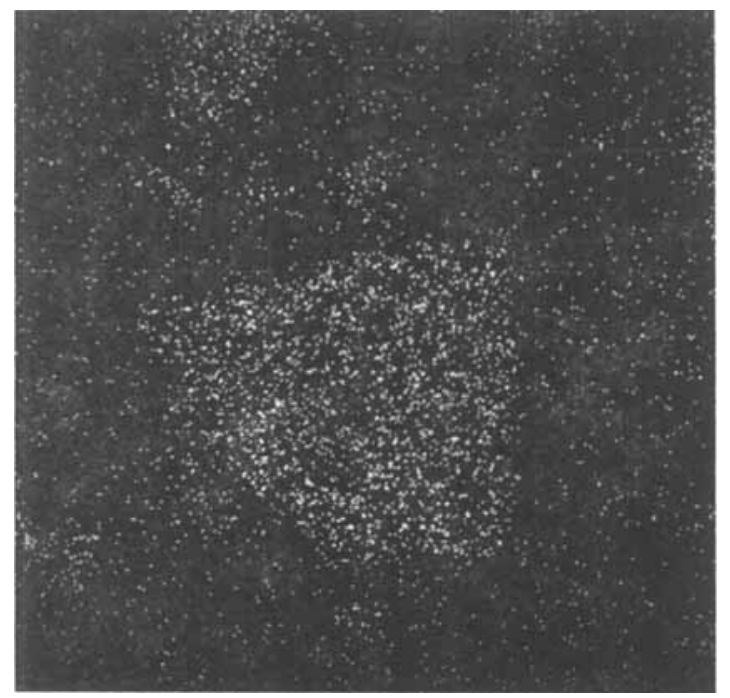

Fig. 12. Electron-beam microprobe photograph of oxygen $X$ radiation from area (1), Fig. 11 . No etch $(\times 1200)$.

(chromium) in the center. This area is coded area (1) and Fig. 12 shows the characteristic oxygen $K$ line from the sample. Similarly, Fig. 13 is a photograph with chromium radiation and Fig. 14. with magnesium. The chromium-rich oxide is apparently low in magnesium. The small spinel grain to the right of the center and the grain on the far right have less chromium and more magnesium.

Figure 15 is the trace of measured radiation characteristic of the magnesium, oxygen, chromium, and nitrogen in the sample, left to right along the line marked by arrows in Fig. 11. The high magnesium content in the small inclusion seen in the characteristic radiation photograph is apparent.

A second area of the same sample of Fig. 11 demonstrated a disparity between magnesium and aluminum contents. Again, where the magnesium content was elevated the chromium content was depressed.

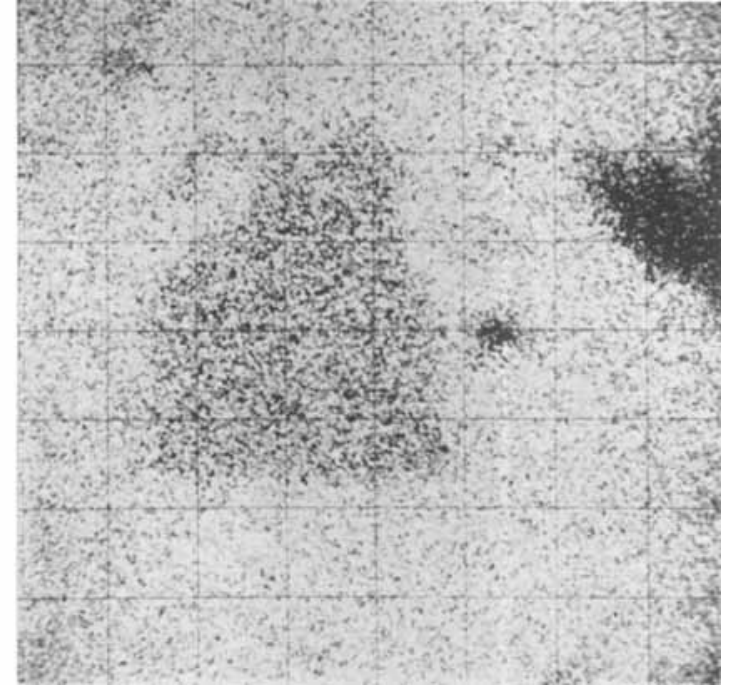

Fig. 13. Electron-beam microprobe photograph of chromium $X$ radiation from area $(1)$, Fig. 11 . No etch $(\times 1200)$.

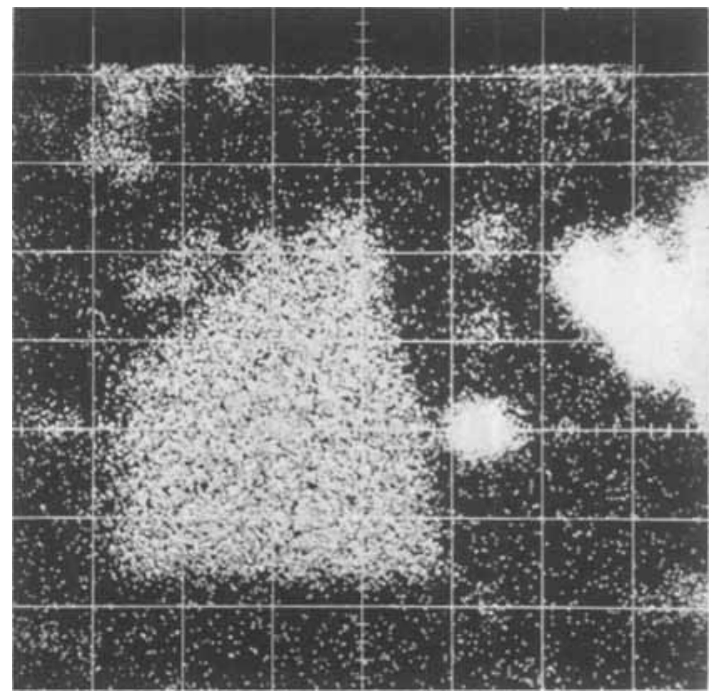

Fig. 14. Electron-beam microprobe photograph of magnesium $X$ radiation from area (1), Fig. 11. No etch $(\times 1200)$.

A number of scatns were performed in a third area, and wherever magnesium content was significant a nitrogen reading several times background count was apparent. Longtime counting was attempted, but the nitrogen count rate decreased with time, presumably because of heating by the electron beam.

A fourth area was examined. The characteristic magnesium radiation was photographed, and a trace was made across the specimen through two spinel particles, one having a high magnesium content. The beam traces for magnesium, chromium, and nitrogen are shown in Fig. 16. The nitrogen count in the right hand spinel particle is statistically significant, representing $0.75 \%$ nitrogen.

\section{(6) Hot-Stage Microscopy}

The apparent decomposition in the electron beam of the spinel phase, which should be quite stable, suggested the use of a vacuum hot-stage microscope to observe the reaction directly. Equilibrium sample 44, made with reagent purity spinel with approximately 3000 ppm nitrogen added, was 


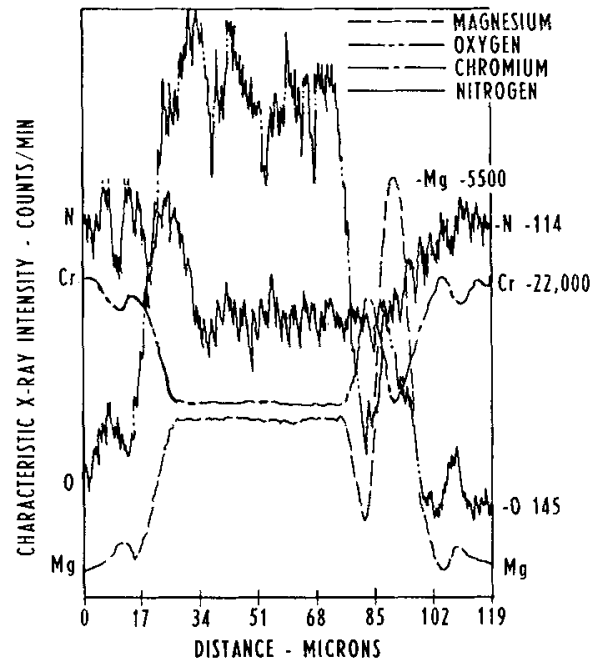

Fig. 15. Line trace of intensity of characteristic $X$ rays from sample 43, area (1), Fig. 11 . No significant difference in nitrogen level is apparent. The small inclusion has more than twice the magnesium content of the large inclusion.

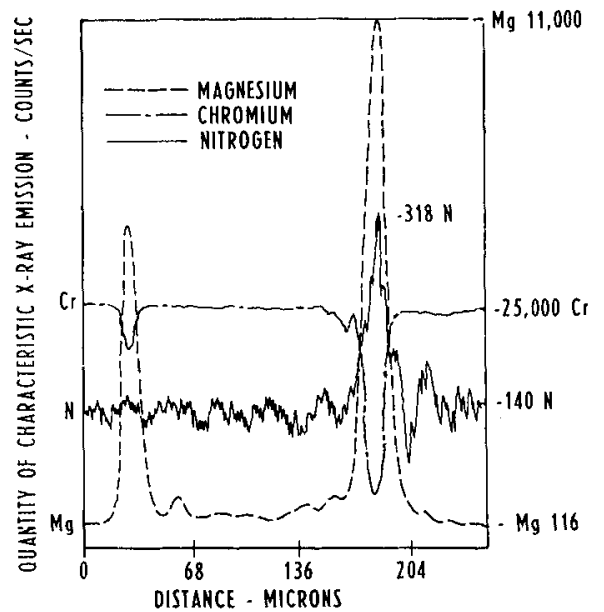

Fig. 16. Line trace of intensity of characteristic $X$ rays from sample 43 , area (4). The nitrogen level in the right hand oxide particle is significantly above background and indicates that nitrogen is associated with the higher magnesium content.

heated in the Vacutherm to $700^{\circ} \mathrm{C}$ at $10^{-5}$ torr. Angular, highly colored spinel grains were unaffected by the heat, whereas the clear white or light yellow grains were definitely affected. Surface rotghening, similar to thermal etching, appeared randomly throughout each of the oxide grains, occurring around the edge, across the center, or throughout the particle

\section{(7) Mass Spectrometer Examination}

A small amount of sample 43 (94 chromium-6 spinel exposed to nitrogen) was prepared by dry-grinding and heated in the ionization chamber of a Bendix Time-of-Flight mass spectrometer. No significant peaks above background appeared until $750^{\circ} \mathrm{C}$ was reached, when a very strong peak occurred at mass number 38 (Fig. 17).

This peak could only be caused by a molectlar combination of $\mathrm{Mg}$ and $\mathrm{N}$ as $\mathrm{MgN}$. No other known combination of the materials present $(\mathrm{Cr}, \mathrm{Mg}, \mathrm{Al}, \mathrm{O}, \mathrm{N})$ would yield this mass number. After a few minutes at $750^{\circ} \mathrm{C}$, further increases in temperature gave no indications above background.

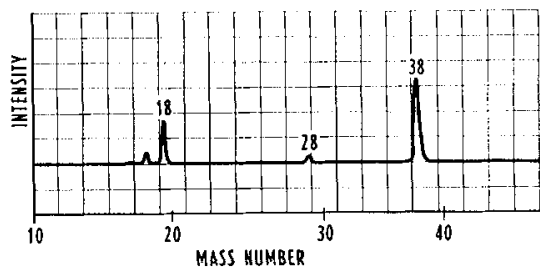

Fig. 17. Mass spectral intensity of gases from sample 43 heated to $750^{\circ} \mathrm{C}$, as a function of mass number. This sample, containing $1360 \mathrm{ppm}$ nitrogen, exhibited a mass number peak at 38 , corresponding to $\mathrm{MgN}$. Other peaks are background corresponding to water vapor, $\mathrm{O}$, and $\mathrm{N}_{2}$, and are present at all temperatures. Note that the abscissa is not a linear scale. Each square represents $17 \mu$.

\section{Discussion}

\section{(1) Reactions of Spinel with Nitrogen and Chromium Nitrides}

Very little reaction was evident between magnesium aluminate or magnesium chromite and either molecular or nascent nitrogen. The small amount of nitrogen absorbed at $1500^{\circ} \mathrm{C}$ could be explained by inaccurate analysis caused by breakdown of spinel containing nitrogen in the moisture present in ordinary air. This result, if real, could also be explained by a small favorable free energy difference in the substitution of nitrogen for oxygen in the spinel and reaction of displaced oxygen with the hydrogen available from the dissociated ammonia.

The extent of reaction of magnesium aluminate with either chromium nitride could not be studied by analyzing for nitrogen content. The extent of reaction of the spinel with chromium, however, could be adequately determined. It is evident that the chromium nitride must break down before significant solution of nitrogen takes place. The larger concentration of chromium dissolved in spinel dispersed in the metal (curve 2, Fig. 4) can be contrasted with the chromium concentration in spinel exposed to the pure nitride (curve 1, Fig. 4). Dissociation of $\mathrm{CrN}$ at $1000^{\circ} \mathrm{C}$ and below did not affect the concentration of chromium in the spinel. The most interesting case is that of spinel in the chromium matrix containing nitrogen in solution. This is discussed in the next section.

\section{(2) Reaction of Chromium-Spinel-Nitrogen Compositions}

Small amounts of nitrogen in chromium precipitate at low temperature because of the limited solubility of nitrogen in chromium. Caplan et al. ${ }^{15}$ published a photomicrograph of chromium containing $60 \mathrm{ppm}$ nitrogen which exhibited extensive Widmanstätten precipitate of dichromium nitride. This type of precipitate was noted in all the spinel-free chromium samples used in this study, as well as in three samples which contained magnesium chromite spinel. Weaver ${ }^{5}$ noted precipitates at the $50 \mathrm{ppm}$ level of nitrogen, in agreement with this study. The minimum nitrogen level causing precipitation is thus extremely low. In the results plotted in Fig. 5 the boundary line is estimated to be accurate to within $20 \mathrm{ppm}$.

The microstructures of $\mathrm{Cr}$-spinel composites which did not contain nitrides prove that nitrogen in solution is partitioned between the chromium and the spinel, and that solution in the spinel is the most favored case. For example, sample 37 has a nitrogen content of $650 \mathrm{ppm}$ overall. The matrix is free of nitrides and contains no more than $20 \mathrm{ppm}$ nitrogen. This means that the spinel at $6 \mathrm{wt} \%$ contains about $1 \%$ nitrogen, in agreement with electron-beam microanalysis. There apparently is also a very slow increase in the nitrogen content in the matrix, as shown by the etch pits exhibited by sample 18 , equilibrated at $1200^{\circ} \mathrm{C}$, and sample 36 , equilibrated at $1300^{\circ} \mathrm{C}$, after quenching. These pits are apparently caused by nitrogen clustered around dislocations. This structure 
evidently results when there is enough dissolved nitrogen (probably less than 5 to $10 \mathrm{ppm}$ ) to cause clustering but not enough to form precipitates. The pits may be confused with precipitates in optical micrographs but may be seen clearly in the electron microscope.

The microstructures indicate that nitrogen is absorbed by spinel and that the partition of nitrogen between chromium and spinel is strongly weighted in favor of the spinel at low nitrogen levels.

\section{(3) Chemical Analysis and Microprobe Analysis}

Chemical analysis of the composites does not separate nitrogen in spinel from nitrogen in chromium. Adams et al. ${ }^{11}$ reported that $\mathrm{AlN}$ in the system $\mathrm{Al}_{2} \mathrm{O}_{3}-\mathrm{AlN}$ could be dissolved from an $\mathrm{Al}_{3} \mathrm{O}_{3} \mathrm{~N}$ spinel structure with dilute $\mathrm{NaOH}$,

The breakdown of many of the spinel grains by heating in the electron beam and by etching suggests that the nitrogen is covalently bonded and probably tetrahedrally coordinated. Blasse $^{17}$ stated that the controlling situation for cation distribution in spinel is that electrostatic considerations lead to very small energy differences for ions other than chromium, and if bonds are stabilized by an effect of nonelectrostatic origin such as covalent bonding, that type of distribution will probably have the lowest energy.

This was confirmed by the mass spectrometer experiment. The nitrogen apparently coordinates with a magnesium ion in the spinel, thus becoming trapped in the spinel lattice and being effectively removed from the chromium matrix. When exposed to the environment at the surface, the nitrogenspinel combination acts very similarly to free $\mathrm{MgN}$. The $750^{\circ} \mathrm{C}$ decomposition temperature in the mass spectrometer corresponds to $700^{\circ} \mathrm{C}$ for the dissociation observed in the hot-stage microscope. These results can be compared to those of Brewer et al., ${ }^{19}$ who reported that trimagnesium dinitricle $\left(\mathrm{Mg}_{3} \mathrm{~N}_{2}\right)$ decomposes at $1130^{\circ} \mathrm{C}$.

The electron-beam microprobe analysis clearly demonstrates that many of the oxide grains have statistically significant nitrogen contents. The fact that many particles do not register nitrogen may well be a function of sample deterioration due to moisture and heat sensitivity. The resulting surface roughness can also significantly lowet the $\mathrm{X}$-ray count. The nitrogen also appears to coexist with an enhanced magnesium content, confirming the coordination of magnesium with nitrogen.

At least two important conclusions can be drawn from the chemical analysis of the chromium-nitrogen samples. Complete acid digestion of $\mathrm{CrN}$ is difficult, or impossible. Formation of alumintum or magnesium nitride, even combined in a spinel phase, requires the same careful handling that the nitride alone would demand. The last conclusion also has relevance in the study of aluminum nitride in nitrided steel, i.e. the AIN may be completely removed by wet grinding or heating during preparation of samples for metallographic examination.

\section{(4) Mechanism of Nitrogen Removal}

\section{The platisible mechanisms of removal are:}

(A) Interstitial Solution of Nitrogen in Spinel: This would be characterized by decreasing solubility with decreasing temperature. The normally low free energies of solution of this type would indicate either loss of nitrogen at low temperature or precipitation of a nitride at low temperature.

(B) Substitutional Solution of $\mathrm{Cr} N$ and/or $\mathrm{Cr}_{2} \mathrm{~N}$ in Spinel: This would be characterized by nearly stoichiometric substitution of the nitride in the spinel, wherein a continuous change in lattice parameter of the spinel would occur until saturation of the spinel and the appearance of a new phase. The cubic lattice structure of $\mathrm{CrN}$ suggests that such solution would be favored and should peak at or below the dissociation temperature of $\mathrm{CrN}$ if this mechanism occurs. The equations for this reaction are:

$$
\begin{aligned}
& x \mathrm{CrN}+\mathrm{MgAl}_{2} \mathrm{O}_{4} \rightleftarrows \mathrm{MgAl}_{2} \mathrm{Cr}_{x} \mathrm{O}_{4} \mathrm{~N}_{x} \\
& x \mathrm{Cr}_{2} \mathrm{~N}+\mathrm{MgAl}_{2} \mathrm{O}_{4} \rightleftarrows \mathrm{MgAl}_{2} \mathrm{Cr}_{2.0} \mathrm{O}_{4} \mathrm{~N}_{x}
\end{aligned}
$$

(C) Reaction of Nitrogen with Spinel in the Presence of Chromium: This would be characterized by dependence on defect formation in the spinel, which would require that chromium nitride be dissociated before the reaction could proceed.

Step 1:

$$
\mathrm{Cr}_{2} \mathrm{~N} \rightleftarrows 2 \mathrm{Cr}+\underline{\mathrm{N}}
$$

Step 2:

$$
2 \underline{\mathrm{N}}+3 \mathrm{MgAl}_{2} \mathrm{O}_{4} \rightleftarrows 3 \mathrm{MgAl}_{2} \mathrm{O}_{3} \mathrm{~N}_{2 / 3}+3 \mathrm{O}
$$

No precipitation or other evidence of decreasing solubility was found, and thus mechanism $(A)$ is not likely. No evidence of direct solution of either $\mathrm{CrN}$ or $\mathrm{Cr}_{2} \mathrm{~N}$ in spinel was discovered (Fig. 4). Moreover, increased nitrogen content was associated with increased magnesium content but not with increased chromium content. Thus mechanism (B) does not seem reasonable. The most likely mechanism is thus substitution (Eqs. (6) and (7)). We envision a continuous series of spinel structures in which chromium is substituted for aluminum and nitrogen for oxygen coordinated with magnesium.

Anderson ${ }^{12}$ discussed a similar situation in regard to the reaction of nitrogen and calcium with calcium oxide. He stated, "Incorporation of nitrogen (in calcium oxide) virtually amounts to substitutional mixed crystal formation with calcium nitride, creating a corresponding number of anion vacancies."

The corresponding situation, that of Eq. (7) above, appears to fit all the data. Other arguments that favor this conclusion are as follows:

(1) Gaseous nitrogen has no effect on spinel in any form to $1200^{\circ} \mathrm{C}$ and slight effect in the form of dissociated ammonia at $1400^{\circ} \mathrm{C}$ and above where nonstoichiometry occurs, and where hydrogen can be assumed to react with any released oxygen.

(2) Chromium is found in considerable quantity in spinel at $1200^{\circ} \mathrm{C}$ and above.

(3) Chemical and microprobe analyses prove that chromium and nitrogen do not exist in spinel in any stoichiometric ratio. Dissociation proceeds by separation of $\mathrm{MgN}$.

(4) Microprobe analysis and hot-stage microscopy indicated a nitrogen spinel with properties similar to those of the $\mathrm{Al}_{3} \mathrm{O}_{3} \mathrm{~N}$ spinel reported by Adams et al. ${ }^{11}$

(5) Oxygen released by the substitution can react readily with chromium in the matrix.

\section{Conclusions}

1. Partitioning of nitrogen between magnesium aluminate spinel and the chromium matrix has been shown to occur. The spinel contains $170 \mathrm{ppm}$ of nitrogen at $1200^{\circ}, 385 \mathrm{ppm}$ at $1300^{\circ}$, and $680 \mathrm{ppm}$ at $1400^{\circ} \mathrm{C}$, where the chromium is saturated with nitrogen after cooling to room temperature.

2. The mechanism of nitrogen removal is one of formation of $\mathrm{N}^{3-}$ ions in anion vacancies present in spinels above $1200^{\circ} \mathrm{C}$ and subsequent coordination with magnesium in the spinel, in agreement with field theory.

3. Dissociation of the nitrogen-containing spinel proceeds by evolution of $\mathrm{MgN}$.

4. Chemical analysis of this system is not possible by phase extraction since the nitrogen-spinel combination breaks down in the extraction process.

5. Electron-beam microprobe analysis for nitrogen in spinel is possible on a semiquantitative basis if care is taken not to decompose the nitrogen-spinel combination during sample preparation, and if the decomposition under the electron beam is recognized.

\section{Acknowledgments}

The authors are indebted to the Bendix Corporation for sponsorship of this work. The tuse of electron-beam microprobes at the ARL Laboratory in Dearborn and at the Ford Motor Company Research Center is also gratefully acknowledged. 
References

${ }^{1}$ D. M. Scruggs, "Modified Chromium for Unprotected Structures," AR.S (Am. Rocket Soc.) J., 31 [11] 1527-33 (1961).

${ }^{2}$ F. Henderson, S. T. M. Johnstone, and H. L. Wain, "Effect of Nitride-Formers upon the Ductile-Brittle Transition in Chromium," J. Inst. Metals, 92 [4] 111-17 (1963-64).

${ }^{3}$ M. J. Klein and A. H. Clauer, "Nitrogen-Induced Internal Friction in Chromium," Trans. AIME, 233 [9] 1771-77 (1965).

${ }^{4}$ F. P. Bullen, F. Henderson, H. L. Wain, and M. S. Patterson, "Effect of Hydrostatic Pressure on Brittleness in Chromium," Phil. Mag., 9 [101] 803-15 (1964).

$5 \mathrm{C}$. W. Weaver, "Strain-Age Hardening and Brittleness in Chromium," Nature, 180, 806-808 (1957).

${ }^{6}$ A. Gilbert and M. J. Klein, "Effect of Cooling Rate on the Ductile-Brittle Bend-Transition Temperature of Chromium Wire," Acta Met., 14 [4] 541-43 (1966).

${ }^{7}$ A. Gilbert, C. N. Reid, and G. T. Hahn, "Observations on the Fracture of Chromium," J. Inst. Metals, 92 [11] 351-56 (196364).

${ }^{8}$ R. E. Hook and A. M. Adair, "Recrystallization Embrittlement of Chromium," Trans. AIME, 227, 151-59 (1963).

${ }^{9}$ D. J. Maykuth, W. D. Klopp, R. I. Jaffee, and H. B. Goodwin, "Metallurgical Evaluation of Iodide Chromium," J. Electrochem. Soc, $102[6] 316-31$ (1955).

${ }^{10}$ G. Blasse, "Crystal Chemistry and Some Magnetic Properties of Mixed Metal Oxides with Spinel Structure," Philips Res. Repts., Suppl., 3, 1-139 (1964).
11 I. Adams, T. R. AuCoin, and G. A. Wolff, "Luminescence in the System $\mathrm{Al}_{2} \mathrm{O}_{3}$-AIN," J. Electrochem. Soc., 109 [11] 1050-54 $(1962)$.

${ }_{12}$ J. S. Anderson; in Non-Stoichiometric Compounds. American Chemical Society, Washington, D. C., 1963.

${ }^{13} \mathrm{R}$. L. Altman and A. W. Searcy; in Symposium on Chemical and Thermodynamic Properties at High Temperatures, 18th International Congress of Pure and Applied Chemistry, Montreal, Canada, 1961.

${ }_{14}$ A. U. Seybolt and R. A. Oriani, "Solubility of Nitrogen in Chromium," J. Metals, 8, 556 (1956).

${ }^{15}$ D. Caplan, M. J. Fraser, and A. A. Burr; pp. 196-215 in Ductile Chromium and Its Alloys. American Society of Metals, Washington, D. C., 1957.

${ }_{16}$ D. K. Bullens, Steel and Its Heat Treatment, Vol. II, 5th ed. John Wiley \& Sons, Inc., New York, 1948.

${ }_{17}$ W. D. Kingery, Property Measurements at High Temperatures. The Technology Press of Massachusetts Institute of Technology, Cambridge, Mass., and John Wiley \& Sons, Inc., New York, 1959.

${ }^{18}$ E. T. Turkdogan and S. Ignatowicz, "Solubility of Nitrogen in Iron-Chromium Alloys," J. Iron Steel Inst., 188 [3] 242-47 (1958).

${ }^{19}$ L. Brewer, L. A. Bromley, P. W. Gilles, and N. L. Lofgren; Paper No. 4 in Chemistry and Metallurgy of Miscellaneous Materials; Thermodynamics. Edited by L. L. Quill. McGrawHill Book Co., New York, 1950.

\title{
Crystallite Growth of Beryllium Oxide Powders and Its Inhibition by Adsorbed Phosphate
}

\author{
G. H. PRICE, W. I. STUART, and D. G. WALKER \\ Australian Atomic Energy Commission Research Establishment, Lucas Heights, New South Wales, Australia
}

\begin{abstract}
Low-temperature sintering of beryllium oxide powders from $300^{\circ}$ to $1000^{\circ} \mathrm{C}$ was studied by measuring crystallite growth and changes in specific surface. Sintering is enhanced by the presence of water vapor. Adsorbed phosphate almost completely inhibits sintering up to $850^{\circ} \mathrm{C}$, even in water vapor at 10 torr.
\end{abstract}

\section{Introduction}

C ALCINATION between about $300^{\circ}$ and $1000^{\circ} \mathrm{C}$ of high-area metal oxide powders often leads to crystallite growth and reduction in specific surface; that is, some form of lowtemperature sintering occurs. Water vapor usually enhances this type of sintering. Anderson and Morgan ${ }^{1}$ showed that rates of crystal growth in magnesitm oxide powder can be increased more than $10^{3}$ times in the presence of water vapor, and steam-sintering of silica and silica-alumina catalysts has been studied. ${ }^{2-6} \mathrm{Rau}^{7}$ demonstrated that considerable crystal growth occurred in beryllium oxide powders on heating in air below $1000^{\circ} \mathrm{C}$.

Mechanisms of low-temperature sintering are not clearly understood, but de Boer and Vleeskens ${ }^{5}$ and Anderson and Morgan ${ }^{1}$ suggested that enhancement in the presence of water vapor occurs because of condensation between surface hydroxyl groups of adjacent crystallites with formation of oxygen bridges. The possibility then arises that, if hydroxyl groups are essential intermediates during sintering in water vapor, the presence of other stable inorganic surface groups

Received December 18, 1967

The writers are, respectively, experimental officer, senior research scientist, and principal research scientist, Australian Atomic Energy Commission. could modify or inhibit sintering. Therefore, low-temperature sintering of beryllium oxide powders was investigated, using surface area measurement, X-ray diffraction techniques, and electron microscopy, with special emphasis on the adsorption of phosphate on beryllium oxide and its effect on sintering.

\section{Experimental Procedure}

\section{(1) Preparation of $\mathrm{BeO}$ Powders}

Powders with surface areas of about 300 to $400 \mathrm{~m}^{2} / \mathrm{g}$ were prepared by vacuum thermal decomposition of $\beta-\mathrm{Be}(\mathrm{OH})_{2}$ or $\mathrm{BeSO}_{4} \cdot 4 \mathrm{H}_{2} \mathrm{O}$. Hydroxide-derived $\mathrm{BeO}(\mathrm{H}-\mathrm{BeO})$ was prepared by heating to $280^{\circ} \mathrm{C}$, and sulfate-derived material (S-BeO) by heating to $950^{\circ} \mathrm{C}$. The temperature was raised slowly to maintain the pressure of gaseous decomposition products below 0.2 torr. Isothermal calcination was then continued until the pressure decreased to about 0.02 torr. The exact form of this temperature program depended on the amount of material used and the geometry of the system. Excellent batchwise reproducibility was obtained in this way.

The $\mathrm{BeO}$ powders were then washed with distilled water until the conductivity of the wash water decreased to about $0.5 \mu \mathrm{mho} / \mathrm{cm}^{2}$.

\section{(2) Measurement of Crystallite Size}

Average crystallite sizes were calculated from $\mathrm{X}$-ray line broadening. X-ray diffraction profiles for the (100) and (002) $\mathrm{Cu} K \alpha$ reflections were obtained using a Philips diffractometer with a chart recorder. Integral breadths were measured for the recorded profiles, corrections for instrumental broadening were made by the method of Klug and Alexander, ${ }^{8}$ and the crystallite size was calculated from the Scherrer formula. 